\title{
EPAC1 overexpression is a prognostic marker and its inhibition shows promising therapeutic potential for gastric cancer
}

\author{
DING-PING SUN ${ }^{1,4}$, CHIA-LANG FANG ${ }^{6,7}$, HAN-KUN CHEN ${ }^{1}$, KUO-SHAN WEN ${ }^{2}$, \\ YOU-CHENG HSEU ${ }^{8,9}$, SHIH-TING HUNG ${ }^{3}$, YIH-HUEI UEN ${ }^{10}$ and KAI-YUAN LIN ${ }^{3,5}$ \\ Departments of ${ }^{1}$ Surgery, ${ }^{2}$ Pharmacy and ${ }^{3}$ Medical Research, Chi Mei Medical Center, Tainan; \\ ${ }^{4}$ Department of Food Science and Technology and ${ }^{5}$ Biotechnology, Chia Nan University of Pharmacy and \\ Science, Tainan; ${ }^{6}$ Department of Pathology, School of Medicine, College of Medicine; ${ }^{7}$ Department of Pathology, \\ Wan Fang Hospital, Taipei Medical University, Taipei; ${ }^{8}$ Department of Cosmeceutics, China Medical University, \\ Taichung; ${ }^{9}$ Department of Health and Nutrition Biotechnology, Asia University, Taichung; \\ ${ }^{10}$ The Superintendent's Office, Chi Mei Hospital Chiali, Tainan, Taiwan, R.O.C.
}

Received September 9, 2016; Accepted February 1, 2017

DOI: 10.3892/or.2017.5442

\begin{abstract}
AMP signaling controls a variety of cellular functions. In addition to the well-known signal transducer cAMP-dependent protein kinase, a more recently discovered transducer is the exchange protein directly activated by cAMP (EPAC). EPAC responses are mediated by small $\mathrm{G}$ proteins, which regulate biologic functions such as cell adhesion, migration and proliferation. Recently, the clinical importance of EPAC1 has received increased attention. This study investigated the correlations between the expression of EPAC1 and various clinicopathologic parameters as well as the survival of the patients with gastric cancer (GC). The patient cohort in this study consisted of 141 cases of GC that presented from 1999 through 2011; documented clinicopathologic parameters and clinical outcomes were available for all cases. Immunoblotting, immunohistochemistry and quantitative real-time PCR were used to examine EPAC1 expression in gastric cells and tissues. siRNA technology was used to study the effect of EPAC1 knockdown on cell proliferation and invasion. An increase in EPAC1 expression was found in GC cells and tissues. The overexpression of EPAC1 was associated with the depth of invasion $(\mathrm{P}=0.0021)$, stage $(\mathrm{P}=0.0429)$, and vascular invasion
\end{abstract}

Correspondence to: Dr Yih-Huei Uen, The Superintendent's Office, Chi Mei Hospital Chiali, 606 Shin-Hwa Road, Chiali, Tainan 722, Taiwan, R.O.C.

E-mail: d970712@mail.chimei.org.tw

Dr Kai-Yuan Lin, Department of Medical Research, Chi Mei Medical Center, 901 Chung-Hua Road, Yungkang, Tainan 710, Taiwan, R.O.C. E-mail: d84306@yahoo.com.tw

Abbreviations: EPAC, exchange protein directly activated by cAMP; GC, gastric cancer

Key words: exchange protein directly activated by cAMP; gastric cancer, prognosis
$(\mathrm{P}=0.0049)$ and was correlated with poor disease-free survival $(\mathrm{P}=0.0029)$ and overall survival $(\mathrm{P}=0.0024)$. A univariate $\mathrm{Cox}$ regression analysis showed that the overexpression of EPAC1 was a prognostic marker for $\mathrm{GC}(\mathrm{P}=0.038)$. Furthermore, cell studies indicated that the knockdown of EPAC1 in GC cells suppressed cell proliferation and invasion. The overexpression of EPAC1 can be used as a marker to predict the outcome of patients with $\mathrm{GC}$, and EPAC1 represents a potential therapeutic modality for treating GC.

\section{Introduction}

Gastric cancer (GC) is the fourth most common cancer and the third most common cause of cancer-related death worldwide (1). Advances in chemotherapy and surgical techniques have increased the survival rate of patients with GC, but the outcome of this common malignancy remains unsatisfactory because of a poor understanding of the pathogenesis of GC and the lack of specific targeted gene therapy $(2,3)$. Since multiple genetic alterations in tumor suppressor genes and oncogenes are involved in gastric carcinogenesis, identifying mechanisms that underlie this malignancy is important (4). The identification of predictive markers for cancer progression and prognosis would aid in the assessment of the clinical outcome and potential treatment stratification for patients with GC (5-9).

cAMP is a second messenger whose signaling controls a variety of functions in cancer cells. However, its role is complex and depends on both the tissue type and the specific cAMP sensor that transduces the signal (10). cAMP signals are mediated by two ubiquitously expressed intracellular receptor families: the classic cAMP-dependent protein kinase (PKA) and the more recently discovered exchange protein directly activated by cAMP (EPAC) (11). EPAC has two isoforms, EPAC1 and EPAC2, which primarily act as guanine nucleotide exchange factors that activate the small $\mathrm{G}$ proteins, Rap1 and Rap2 (12). These small G proteins in turn mediate the vast majority of EPAC responses, which span a wide array of 
biologic functions, including the regulation of cell adhesion, migration and proliferation, in different cell types (13).

Gene amplification and protein overexpression of EPAC1 are observed in several human cancers, including pancreatic cancer and melanoma. In one study, the expression levels of EPAC1 protein were examined by immunohistochemistry in pancreatic tissues. The staining was markedly enhanced in pancreatic cancer tissues compared with surrounding normal tissues (14). In another study, quantitative real-time PCR also confirmed significantly higher levels of EPAC1 in metastatic melanoma compared with primary melanoma (15). The clinical significance of EPAC1 has gained increased attention in recent years, and many studies have focused on the relationship between EPAC1 and cancer cell migration. The role that EPAC1 plays in the regulation of cancer cell migration is controversial, and it appears to be dependent on the tissue type. In melanoma, the consensus states that EPAC1 enhances metastasis, as shown in several in vitro and in vivo studies $(16,17)$. In prostate cancer, some studies suggest that EPAC1 promotes migration and proliferation $(18,19)$, whereas others suggest an inhibitory role for the EPAC-selective activator 8-(4-chlorophenylthio)-29-O-methyladenosine-39, 59-cyclic monophosphate (007) (13). However, it has been argued that it is actually the indirect activation of cAMPdependent protein kinase by 007 , not the activation of EPAC1, that leads to the inhibition of migration and proliferation of prostate cancer cells (20). In ovarian cancer, EPAC1 seems to exert promigratory effects in some cell lines (Ovcar3) (21) and antimigratory effects in others (ES-2) (22).

Thus far, the correlations between the EPAC1 expression level in GC and clinicopathologic parameters and prognosis have not been established. Therefore, this study investigated the correlations between EPAC1 expression and clinicopathologic parameters and evaluated the significance of EPAC1 in the prediction of the prognosis of patients with GC.

\section{Material and methods}

Participants and specimens. The patient cohort examined in this study comprised 141 consecutive GC cases from 1999 through 2011 with documented clinicopathologic factors and clinical outcomes. None of these patients had received preoperative chemotherapy and/or radiotherapy. For each patient, we analyzed paired tumor and non-tumor gastric tissues to determine the expression of EPAC1. The institutional review board at Wan Fang Hospital approved the tissue acquisition protocol for the immunohistochemical and quantitative real-time PCR study (approval no. 99049). Written informed consent was obtained from each participant before tissue acquisition.

Immunohistochemical analysis. Paraffin-embedded sections were deparaffinized, rehydrated and subjected to antigen retrieval ( $\mathrm{pH} 6.0$ citrate buffer for $40 \mathrm{~min}$ at $95^{\circ} \mathrm{C}$ ). After blocking with 5\% normal goat serum (Abcam, Cambridge, UK), the slides were subsequently incubated with the primary antibody rabbit anti-human EPAC1 monoclonal antibody (LifeSpan Biosciences, Seattle, WA, USA) for $45 \mathrm{~min}$ at room temperature at a dilution of 1:200. The immunoreactivity was detected using the avidin-biotin-peroxidase complex method
Table I. Primers used in quantitative real-time PCR.

\begin{tabular}{lc}
\hline Gene & \multicolumn{1}{c}{ Sequence } \\
\hline EPAC1 & Forward: ccgaagctgctcctacca \\
& Reverse: actcctcgctgttggtgagt \\
GAPDH & Forward: acagttgccatgtagacc \\
& Reverse: ttttggttgagcacagg \\
\hline
\end{tabular}

according to the manufacturer's instructions. A sensitive Dako Real EnVision Detection System was used (Dako North America, Carpinteria, CA, USA). Normal kidney was used as a positive control for EPAC1. The sections were then scored using a semi-quantitative scoring system that accounted for staining intensity ( 0 , no staining; 1 , weak staining; 2 , strong staining) and the fraction of positively stained tumor cells $(0$, no staining; 1 , less than half of cells stained; 2 , more than half of cells stained). The final score was calculated for each sample by multiplying the score for the intensity and the score for the percentage of staining: 0 , no staining; 1 , weak staining; 2 , moderate staining; 4 , strong staining. Sections with a score of 0 or 1 displayed low expression of EPAC1, whereas those with scores of 2 or 4 displayed high expression or overexpression of EPAC1. The collection of clinical data and the immunohistochemical analysis were performed independently of each other in an investigator-blinded study.

RNA extraction and $c D N A$ synthesis. According to the manufacturer's instructions, total RNA from 10 tumor and non-tumor pairs of gastric tissues was isolated using an RNA extraction kit (Zymo Reserach, Irvine, CA, USA). cDNA synthesis was performed as described in our previous study (23). Synthesized cDNA was stored at $-20^{\circ} \mathrm{C}$ until use.

Primers and quantitative real-time PCR. Primers for EPAC1 and GAPDH, which was used as an internal control, and realtime PCR master mix (KiCqStart SYBR Green qPCR Ready Mix) were purchased from Sigma (St. Louis, MO, USA). Primer sequences are shown in Table I. The expression levels of the target genes were measured using quantitative real-time PCR in an Illumina Eco Real-time PCR System (Illumina, San Diego, CA, USA). The level of EPAC1 mRNA in tumor and non-tumor tissue was determined relative to GAPDH.

Cell culture. The normal human gastric cell line Hs738.St/Int was obtained from the American Type Culture Collection (ATCC, Manassas, VA, USA). The GC cell lines NCI-N87, TMC-1 and TSGH 9201 were obtained from the Bioresource Collection and Research Center (BCRC, Hsinchu, Taiwan). The GC cell lines SK-GT-2 and HGC-27 were obtained from the European Collection of Cell Cultures (ECACC, Salisbury, UK), and the GC cell line 23132/87 was obtained from Creative Bioarray (Shirley, NY, USA). Cells were cultured in DMEM (Gibco, Grand Island, NY, USA, for Hs738.St/Int), RPMI-1640 (Gibco, for NCI-N87, TMC-1, TSGH 9201, SK-GT-2 and 23132/87), MEM (Mediatech, Manassas, VA, USA for HGC-27) media supplemented with $10 \%$ fetal bovine serum 
(FBS), $100 \mathrm{U} / \mathrm{ml}$ penicillin $\mathrm{G}, 100 \mu \mathrm{g} / \mathrm{ml}$ streptomycin sulfate, and $250 \mathrm{ng} / \mathrm{ml}$ amphotericin B (Gibco).

Total protein preparation. Total protein was extracted using M-PER Mammalian Protein Extraction Reagent (Pierce Biotechnology, Rockford, IL, USA), according to the manufacturer's instructions. The samples were stored at $-80^{\circ} \mathrm{C}$ until use. The protein concentration was determined using a BCA Protein assay kit (Pierce Biotechnology) with bovine serum albumin as the standard.

Immunoblotting. Denatured protein samples were subjected to SDS-PAGE and transferred to nitrocellulose membranes. After blocking with 5\% non-fat dry milk (Santa Cruz Biotechnology, Dallas, TX, USA), the membranes were incubated with an antiEPAC1 polyclonal antibody (1:1000 dilution) at $4^{\circ} \mathrm{C}$ overnight and were further incubated with the appropriate peroxidaseconjugated secondary antibody (Sigma) for $1 \mathrm{~h}$ at room temperature. Reactive bands were detected using Western Lighting ECL Pro chemiluminescent substrate (Perkin-Elmer, Waltham, MA, USA) The band intensity was quantitatively analyzed using Fuji Image Gauge software (Fuji Co., Tokyo, Japan), and the absolute intensity of EPAC1 was normalized to the absolute intensity of GAPDH.

siRNA treatment. SK-GT- 2 cells were seeded at $50 \%$ confluence. For siRNA treatment, cells were transfected with siRNAs (two EPAC1-siRNAs, oligo no. 8022287661-000080 and 8022287661-000110; and one control, oligo no. 8022065260000020, purchased from Sigma) at a concentration of $10 \mathrm{nM}$ by using MISSION siRNA Transfection Reagent (Sigma). After transfection, the knockdown efficiency was examined by immunoblotting.

Colony formation assay. Five hundred cells were seeded into 6-well plates and cultured for 12 days. Individual colonies ( $>50$ cells/colony) were fixed, stained in a solution of $1 \%$ crystal violet in methanol, and counted. The plates were scanned with a Scanjet 2200c scanner (Hewlett-Packard, Palo Alto, CA, USA). After scanning, methanol was added to solubilize crystal violet at room temperature with shaking. The optical density $\left(\mathrm{OD}_{540}\right)$ was measured to quantify the amount of colony formation. The assay was performed three times, and the results are presented as the mean \pm the standard deviation (SD).

Cell invasion assay. The cell invasion capability was examined with a Cell Invasion assay kit (Merck Millipore, Darmstadt, Germany) according to the manufacturer's instructions. Complete media were first added to 24 -well plates. Then, cells $\left(2 \times 10^{5}\right)$ in serum-free media were added to ECMatrixlayered cell culture inserts (containing polycarbonate membranes with pores $8 \mu \mathrm{m}$ in diameter) and cultured for $72 \mathrm{~h}$. After the cells on the upper surface were removed, the inserts were then dipped in staining solution to stain the cells that had invaded the lower surface of the membranes. The cultures were imaged (x100 magnification), using a Leica DMIRB microscope (Wetzlar, Germany). The number of invaded cells was counted. The assay was performed three times, and the results are presented as the mean $\pm \mathrm{SD}$.
Statistical analysis. Paired t-tests were used to assess the difference in EPAC1 expression between tumor and nontumor tissues for each patient. The differences in growth and invasion between EPAC1 knockdown and control cells were analyzed using Student's t-tests. We also examined the following clinicopathological parameters: age, gender, depth of invasion, nodal status, distant metastasis, stage, degree of differentiation, and vascular invasion. The correlation between EPAC1 expression and each clinicopathological parameter was examined using the $\chi^{2}$ test. The time-to-event endpoints for the parameters were plotted according to the Kaplan-Meier method, and the degree of significance was calculated by the univariate log-rank test. Parameters that emerged as significant $(\mathrm{P} \leq 0.05)$ in univariate Cox regression analysis were entered as variables in the multivariate Cox regression model; the hazard ratio (HR) and independent prognostic impact were determined in a stepwise backward fashion. All data were analyzed using SPSS software version 20.0 (SPSS, Chicago, IL, USA), and a P-value of $<0.05$ was considered significant.

\section{Results}

Basic data. This study enrolled 141 patients with GC; of these, 90 were men, and 51 were women (Table II). The age of the patients ranged from 32 to 96 years at the time of first diagnosis (mean, 68.7 years). According to the AJCC classification system, 25 patients had stage I disease, 38 had stage II, 59 had stage III, and 19 had stage IV disease. The follow-up period for all patients ranged from 30 to 3498 days (mean, 925 days). During the follow-up period, 88 patients died as a result of GC.

EPACl expression is upregulated and associated with several clinicopathological parameters in GC. To investigate the potential significance of EPAC1 in the development and progression of GC, we first examined the expression of EPAC1 in gastric cell lines. As shown in Fig. 1A, immunoblotting revealed that EPAC1 protein expression was markedly increased in all 6 GC cell lines compared with Hs738.St/Int cells. An independent cohort comprised of $141 \mathrm{GC}$ patients was enrolled to validate the results from cellular study. Immunohistochemical analysis showed that EPAC1 was expressed at higher levels in tumor tissues compared with non-tumor tissues $(\mathrm{P}<0.001)$ (Fig. 1B). Eleven percent of the tumors were completely negative for EPAC1 (score 0), and 35\% of the tumors showed weak staining in $<50 \%$ of the tumor cells (score 1) (Fig. 1C). Fifty-four percent of the tumors revealed high expression or overexpression of EPAC1 (48\% had a score of 2, and 6\% had a score 4, Fig. 1D). Quantitative real-time PCR analysis also indicated that EPAC1 mRNA was ubiquitously expressed at higher levels in GC tissues compared with normal gastric tissues (Fig. 1E). These data strongly suggested that EPAC1 expression is significantly elevated in GC.

The observed upregulated expression of EPAC1 in GC prompted us to further investigate the clinical relevance of EPAC1 in the progression of GC. As shown in Table III, the overexpression of EPAC1 was closely associated with depth of invasion $(\mathrm{P}=0.0021)$, stage $(\mathrm{P}=0.0429)$, and vascular invasion $(\mathrm{P}=0.0049)$. Representative photomicrographs of EPAC1 expression for the different parameters are shown 


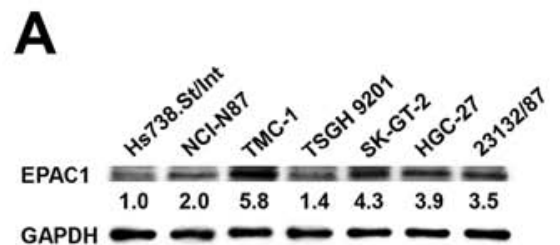

E

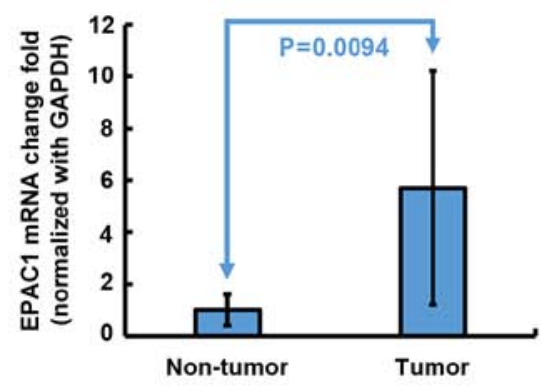

B

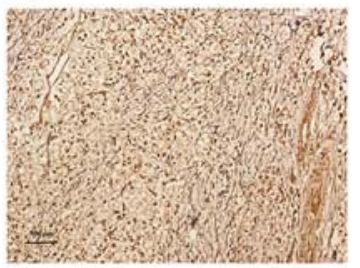

F $\quad \mathrm{T} 1+\mathrm{T} 1$

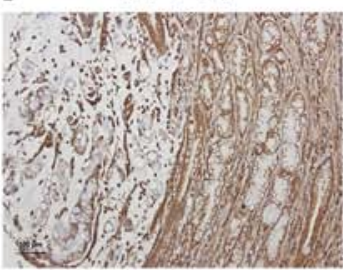

$\mathrm{T} 3+\mathrm{T} 4$

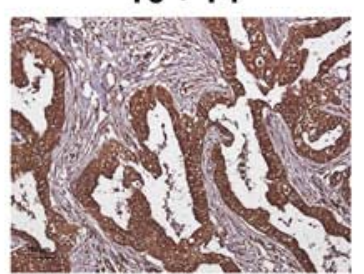

C

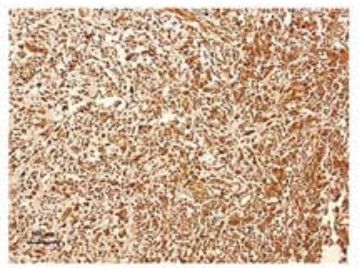

Stage I + II

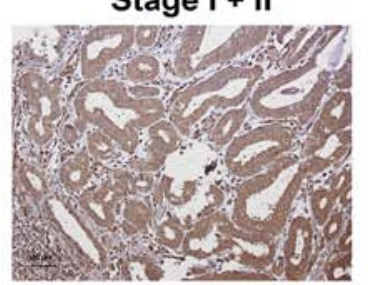

Stage III + IV

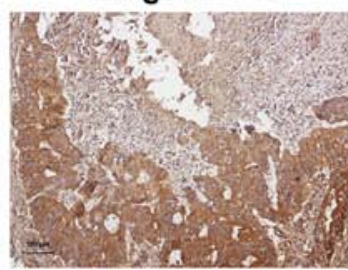

D

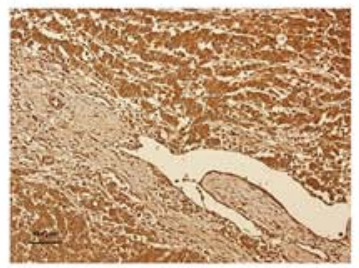

Vascular invasion (-)

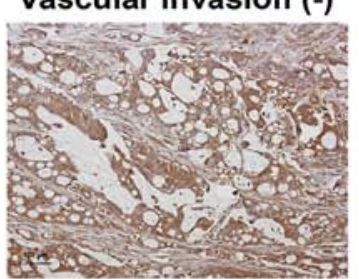

Vascular invasion (+)

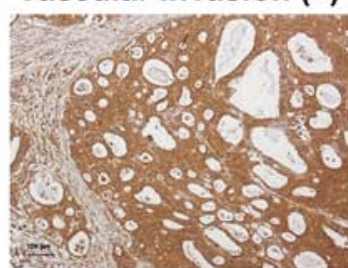

Figure 1. Expression of EPAC1 in gastric cells and tissues. EPAC1 protein expression was significantly increased in gastric cancer (GC) cell lines (A) and tissues (B-D). (B) A sample of non-tumor tissue with low EPAC1 expression; (C) a tumor specimen with low EPAC1 expression; (D) a tumor specimen with high EPAC1 expression. (E) EPAC1 mRNA fold-change in the gastric tissues (presented as the mean $\pm \mathrm{SD}, \mathrm{P}=0.0094$ ). Significance level: $\mathrm{P}<0.05$. (F) The representative EPAC1 staining for different parameters.

A

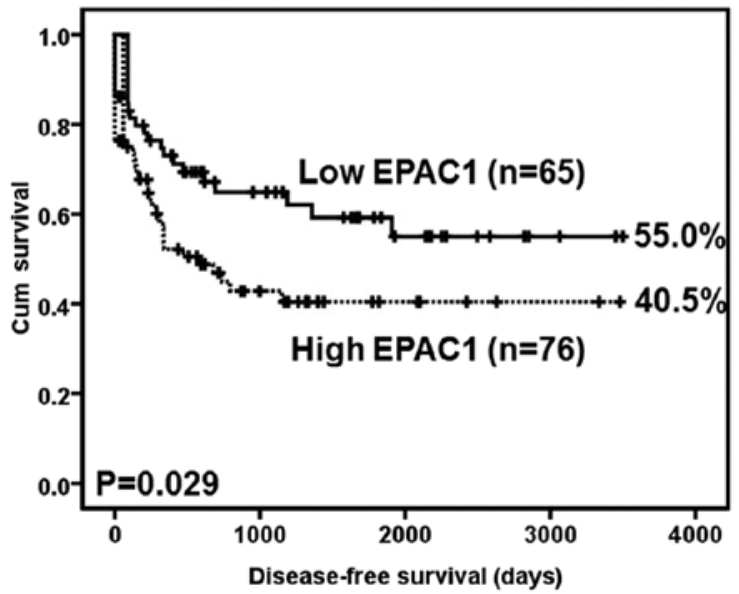

B

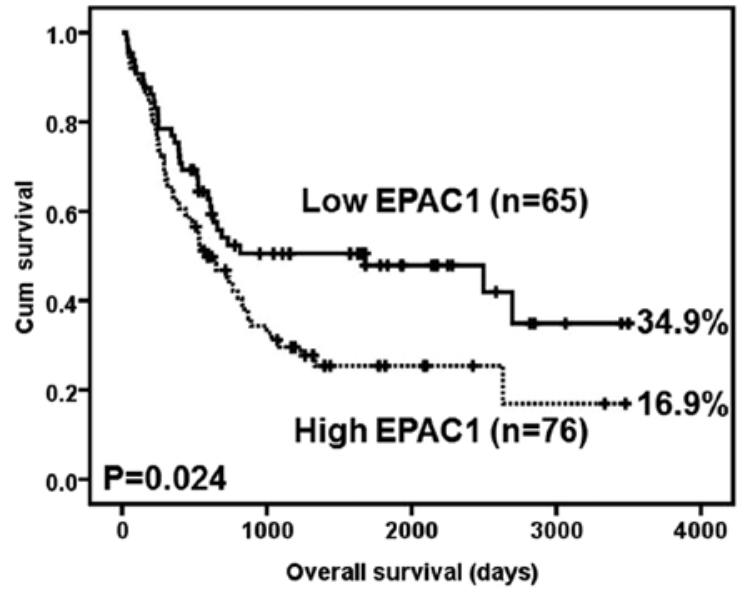

Figure 2. Survival analysis of gastric cancer (GC) patients stratified by EPAC1 immunoreactivity (low EPAC1: score $=0$ or 1; high EPAC1: score=2 or 4). (A) The disease-free survival of 141 patients with GC. (B) The overall survival of 141 patients with GC. All statistical tests were two-sided. Significance level: $\mathrm{P}<0.05$.

in Fig. 1F. No significant association was found between the overexpression of EPAC1 and the other clinicopathological parameters examined.

Overexpression of EPACl as a prognostic marker for GC. A Kaplan-Meier analysis using the log-rank test showed that EPAC1 overexpression was significantly associated with inferior disease-free survival ( $\mathrm{P}=0.029)$ (Fig. 2A). At 5 years, 15 EPAC1-low patients were at risk, and the disease-free survival rate was 0.592 [95\% confidence interval (CI) 0.4568-0.7272]; moreover, 6 EPAC1-high patients were at risk, and the diseasefree survival rate was 0.405 (95\% CI, 0.2815-0.5285).

EPAC1 overexpression was also significantly associated with inferior overall survival $(\mathrm{P}=0.024)$ (Fig. 2B). At 5 years, 16 EPAC1-low patients were at risk, and the overall survival rate was 0.479 (95\% CI, 0.3496-0.6084); moreover, 6 EPAC1-high patients were at risk, and the overall survival rate was 0.254 (95\% CI, 0.3618-0.8698).

Table IV summarizes the univariate analysis of prognostic markers and patient survival. The following parameters were 
Table II. Demographic data and survival in different stages of GC according to the AJCC classification.

\begin{tabular}{|c|c|c|c|c|c|}
\hline Variables & $\begin{array}{l}\text { Stage I } \\
(\mathrm{n}=25)\end{array}$ & $\begin{array}{l}\text { Stage II } \\
(\mathrm{n}=38)\end{array}$ & $\begin{array}{c}\text { Stage III } \\
(n=59)\end{array}$ & $\begin{array}{c}\text { Stage IV } \\
(\mathrm{n}=19)\end{array}$ & $\begin{array}{c}\text { Total } \\
(\mathrm{n}=141)\end{array}$ \\
\hline \multicolumn{6}{|l|}{ Gender } \\
\hline Male & 15 & 23 & 40 & 12 & 90 \\
\hline Female & 10 & 15 & 19 & 7 & 51 \\
\hline Age $\left(\right.$ years) ${ }^{\mathrm{a}}$ & $67.3(12.7)$ & $74.7(12.4)$ & $69.2(14.0)$ & $57.4(14.9)$ & $68.7(14.3)$ \\
\hline Follow-up period (days) ${ }^{\mathrm{a}}$ & $1386.9(952.1)$ & $1097.1(859.1)$ & $800.0(812.7)$ & $363.1(270.8)$ & $925.2(853.9)$ \\
\hline \multicolumn{6}{|l|}{ Survival } \\
\hline Yes & $18(72 \%)$ & $20(53 \%)$ & $13(22 \%)$ & $2(11 \%)$ & $53(38 \%)$ \\
\hline No & $7(28 \%)$ & $18(47 \%)$ & $46(78 \%)$ & $17(89 \%)$ & $88(62 \%)$ \\
\hline
\end{tabular}

${ }^{a}$ Age and follow-up period are expressed as the mean (SD).

Table III. EPAC1 expression in GC and its correlation with clinicopathological parameters.

\begin{tabular}{|c|c|c|c|c|}
\hline \multirow[b]{2}{*}{ Variables } & \multirow[b]{2}{*}{$\mathrm{n}$} & \multicolumn{2}{|c|}{ EPAC1 expression } & \multirow[b]{2}{*}{ P-value } \\
\hline & & $\begin{array}{l}\text { Score } 0 \text { or } 1 \\
\qquad(n=65)\end{array}$ & $\begin{array}{l}\text { Score } 2 \text { or } 4 \\
\quad(n=76)\end{array}$ & \\
\hline Age (yrs.) & & & & 0.2974 \\
\hline$\geq 66$ & 91 & 39 & 52 & \\
\hline$<66$ & 50 & 26 & 24 & \\
\hline Gender & & & & 0.6005 \\
\hline Male & 90 & 40 & 50 & \\
\hline Female & 51 & 25 & 26 & \\
\hline Lauren classification & & & & 0.7747 \\
\hline Intestinal & 95 & 43 & 52 & \\
\hline Diffuse & 46 & 22 & 24 & \\
\hline Depth of invasion & & & & 0.0021 \\
\hline $\mathrm{T} 1+\mathrm{T} 2$ & 35 & 24 & 11 & \\
\hline $\mathrm{T} 3+\mathrm{T} 4$ & 106 & 41 & 65 & \\
\hline Nodal status & & & & 0.2381 \\
\hline N0 & 45 & 24 & 21 & \\
\hline $\mathrm{N} 1+\mathrm{N} 2+\mathrm{N} 3$ & 96 & 41 & 55 & \\
\hline Distant metastasis & & & & 0.0629 \\
\hline Absent & 122 & 60 & 62 & \\
\hline Present & 19 & 5 & 14 & \\
\hline Stage & & & & 0.0429 \\
\hline I + II & 63 & 35 & 28 & \\
\hline III + IV & 78 & 30 & 48 & \\
\hline Degree of differentia & ion & & & 0.4696 \\
\hline Poor & 61 & 26 & 35 & \\
\hline Well to moderate & 80 & 39 & 41 & \\
\hline Vascular invasion & & & & 0.0049 \\
\hline Absent & 44 & 28 & 16 & \\
\hline Present & 97 & 37 & 60 & \\
\hline
\end{tabular}

${ }^{a}$ All statistical tests were two-tailed and the significance level was set as $\mathrm{P}<0.05$. significantly correlated with disease-free survival: EPAC1 overexpression (HR, 1.714; 95\% CI, 1.031-2.850; $\mathrm{P}=0.038$ ), Lauren classification (HR, 1.743; 95\% CI, 1.060-2.865; P=0.029), depth of invasion (HR, 5.158; 95\% CI, 2.064-12.890; $\mathrm{P}<0.001$ ), nodal status (HR, 8.656; 95\% CI, 3.456-21.680; $\mathrm{P}<0.001)$, distant metastasis (HR, 14.607; 95\% CI, 6.440-33.133; $\mathrm{P}<0.001$ ), stage (HR, 8.098; 95\% CI, 3.973-16.510; P<0.001), degree of differentiation (HR, 0.464; 95\% CI, 0.282-0.762; $\mathrm{P}=0.002$ ), and vascular invasion (HR, 5.332; 95\% CI, 2.419-11.571; $\mathrm{P}<0.001$ ). In the multivariate analysis, distant metastasis (HR, 8.647; 95\% CI, 3.603-20.751; $\mathrm{P}<0.001)$ was still an independent prognostic marker. EPAC1 overexpression, however, was not prognostically independent (HR, 1.087; 95\% CI, 0.626-1.890; $\mathrm{P}=0.766$ ) (Table V).

Silencing EPAC1 suppresses GC cell proliferation and invasion. Based on their high expression level of EPAC1, SK-GT-2 GC cells were selected to investigate the role of endogenous EPAC1 in the modulation of cell proliferation. SK-GT-2 cells were transfected with EPAC1-siRNA to generate EPAC1knockdown SK-GT-2 cells (Fig. 3A). As shown in Fig. 3B, the ability of SK-GT-2 cells to form colonies was compromised by EPAC1 knockdown compared with the corresponding control cells. These results suggested that the knockdown of EPAC1 suppresses the ability of GC cells to proliferate in vitro.

Furthermore, according to the results of the clinicopathologic correlation study, which showed that EPAC1 overexpression was closely associated with depth of invasion and vascular invasion, the effect of EPAC1 knockdown on the invasiveness of SK-GT-2 GC cells was examined. In the cell invasion assay, EPAC1 knockdown significantly suppressed SK-GT-2 cell invasion compared with the control cells (Fig. 3C).

\section{Discussion}

Surgical resection is generally considered the best treatment to improve prognosis when the early diagnosis of gastric cancer (GC) is successful (24). Unfortunately, most cases of GC are already locally advanced and are thus at a late stage at the time of diagnosis. Greater knowledge of the molecular mechanisms underlying the development of this 
Table IV. Univariate analysis of prognostic markers in 141 patients with GC.

\begin{tabular}{|c|c|c|}
\hline Variables & $\operatorname{HR}(95 \% \mathrm{CI})^{\mathrm{a}}$ & P-value ${ }^{a}$ \\
\hline EPAC1 & $1.714(1.031-2.850)$ & 0.038 \\
\hline \multicolumn{3}{|l|}{ Low expression } \\
\hline \multicolumn{3}{|l|}{ High expression } \\
\hline Age (yrs.) & $0.804(0.489-1.323)$ & 0.391 \\
\hline \multicolumn{3}{|l|}{$\geq 66$} \\
\hline \multicolumn{3}{|l|}{$<66$} \\
\hline Gender & $0.709(0.417-1.204)$ & 0.203 \\
\hline \multicolumn{3}{|l|}{ Male } \\
\hline \multicolumn{3}{|l|}{ Female } \\
\hline Lauren classification & $1.743(1.060-2.865)$ & 0.029 \\
\hline \multicolumn{3}{|l|}{ Intestinal } \\
\hline \multicolumn{3}{|l|}{ Diffuse } \\
\hline Depth of invasion & $5.158(2.064-12.890)$ & $<0.001$ \\
\hline \multicolumn{3}{|l|}{$\mathrm{T} 1+\mathrm{T} 2$} \\
\hline \multicolumn{3}{|l|}{$\mathrm{T} 3+\mathrm{T} 4$} \\
\hline Nodal status & $8.656(3.456-21.680)$ & $<0.001$ \\
\hline \multicolumn{3}{|l|}{ NO } \\
\hline \multicolumn{3}{|l|}{$\mathrm{N} 1+\mathrm{N} 2+\mathrm{N} 3$} \\
\hline Distant metastasis & $14.607(6.440-33.133)$ & $<0.001$ \\
\hline \multicolumn{3}{|l|}{ Absent } \\
\hline \multicolumn{3}{|l|}{ Present } \\
\hline Stage & $8.098(3.973-16.510)$ & $<0.001$ \\
\hline \multicolumn{3}{|l|}{ I + II } \\
\hline \multicolumn{3}{|l|}{ III + IV } \\
\hline Degree of differentiation & $0.464(0.282-0.762)$ & 0.002 \\
\hline \multicolumn{3}{|l|}{ Poor } \\
\hline \multicolumn{3}{|l|}{ Well to moderate } \\
\hline Vascular invasion & $5.332(2.419-11.571)$ & $<0.001$ \\
\hline \multicolumn{3}{|l|}{ Absent } \\
\hline Present & & \\
\hline
\end{tabular}

aAll statistical tests were two-tailed and the significance level was set as $\mathrm{P}<0.05$. HR, hazard ratio; $\mathrm{CI}$, confidence interval.

deadly neoplasm is required if novel strategies for prevention and treatment of GC are to be developed. In particular, the identification of molecules that are altered during cancer progression may lead to the use of those molecules as prognostic markers or therapeutic targets.

After sensing cAMP, EPAC activates the small $\mathrm{G}$ proteins Rap1 and Rap2, which in turn regulate a wide array of biologic properties, including cell adhesion, migration and proliferation, in different cell types $(25,26)$. The expression of EPAC1 in human cancers varies according to cancer type. A survey of a public human protein atlas database indicated that the protein level of EPAC1 is increased in numerous human cancers, including pancreatic cancer and melanoma, whereas it is decreased in endometrial cancer. To our knowledge, no
A

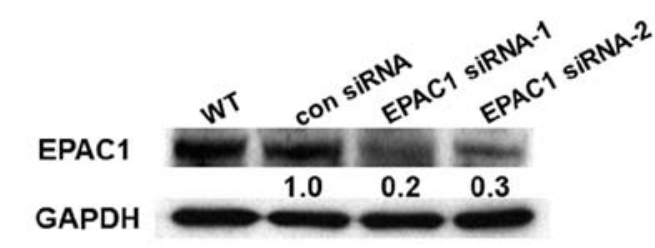

B
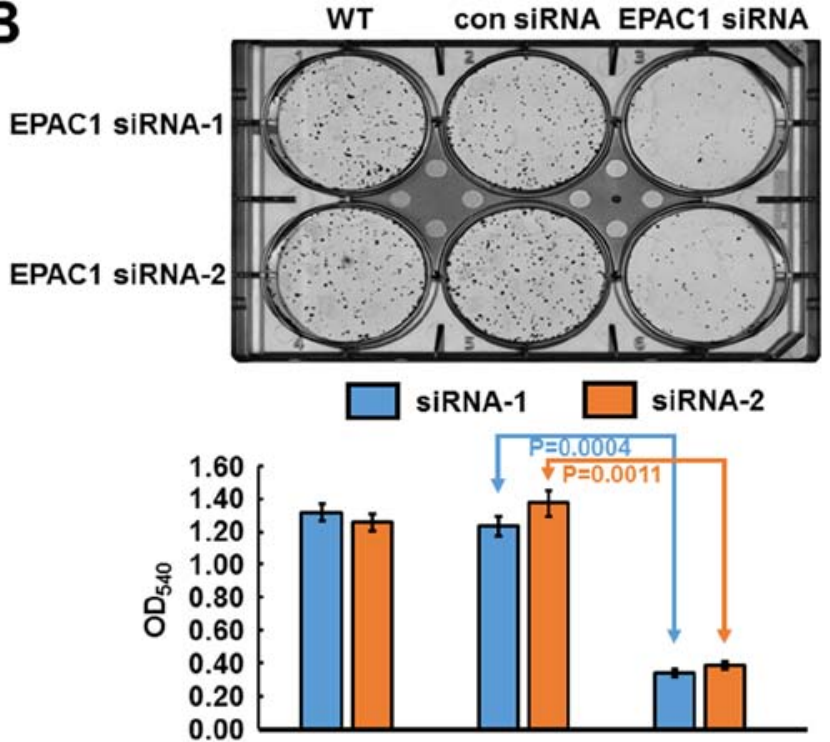

C

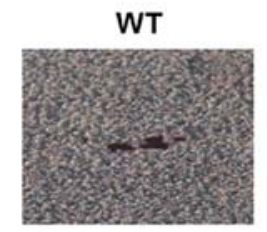

con SIRNA

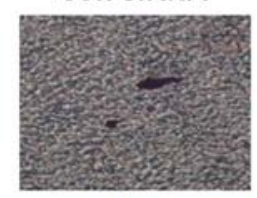

EPAC1 siRNA-1

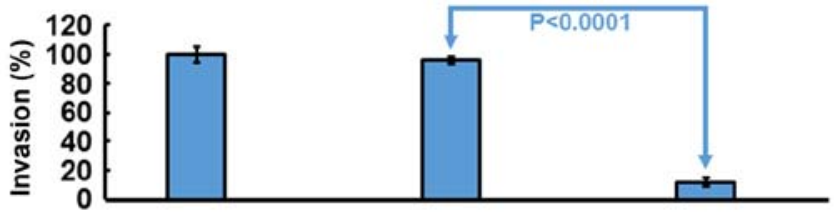

Figure 3. Verification of EPAC1 knockdown in SK-GT-2 cells, and the effect of EPAC1 knockdown on cell proliferation and invasion. For siRNA treatment, cells were transfected with siRNAs at a concentration of $10 \mathrm{nM}$ by using MISSION siRNA Transfection Reagent. The immunoblotting results (A) indicate that EPAC1 was efficiently knocked down by siRNA treatment. (B) Inhibition of EPAC1 expression by two different siRNAs suppressed cell proliferation. The histogram represents OD540 (presented as the mean \pm SD, $P=0.0004$ and 0.0011 , respectively). Significance level: $P<0.05$. (C) Silencing EPAC1 expression repressed cell invasion. The histogram represents the number of invaded cells (presented as the mean $\pm S D, P<0.0001$ ). Significance level: $\mathrm{P}<0.05$.

study has investigated the expression of EPAC1 in human GC. In the present study, we assessed the expression level of EPAC1 in gastric cells and tissues. The immunoblotting and immunohistochemistry data indicated that EPAC1 expression was significantly elevated in gastric tumor tissues and cells compared with non-tumor gastric tissues and cells, which was consistent with results in pancreatic cancer and melanoma. The proliferation of cancer cells is a key event in cancer progression (27). Furthermore, RNA silencing experiments have also shown that the abrogation of EPAC1 could suppress cancer cell proliferation, which indicates that EPAC1 is necessary for 
Table V. Multivariate analysis of prognostic markers in 141 patients with GC.

\begin{tabular}{|c|c|c|}
\hline Variables & $\operatorname{HR}(95 \% \mathrm{CI})^{\mathrm{a}}$ & P-value ${ }^{a}$ \\
\hline $\begin{array}{l}\text { EPAC1 } \\
\text { Low expression } \\
\text { High expression }\end{array}$ & $1.087(0.626-1.890)$ & 0.766 \\
\hline $\begin{array}{l}\text { Lauren classification } \\
\text { Intestinal } \\
\text { Diffuse }\end{array}$ & $0.694(0.319-1.510)$ & 0.357 \\
\hline $\begin{array}{l}\text { Depth of invasion } \\
\mathrm{T} 1+\mathrm{T} 2 \\
\mathrm{~T} 3+\mathrm{T} 4\end{array}$ & $1.424(0.479-4.231)$ & 0.525 \\
\hline $\begin{array}{l}\text { Nodal status } \\
\text { N0 } \\
\mathrm{N} 1+\mathrm{N} 2+\mathrm{N} 3\end{array}$ & $2.614(0.775-8.819)$ & 0.121 \\
\hline $\begin{array}{l}\text { Distant metastasis } \\
\text { Absent } \\
\text { Present }\end{array}$ & $8.647(3.603-20.751)$ & $<0.001$ \\
\hline $\begin{array}{l}\text { Stage } \\
\text { I + II } \\
\text { III + IV }\end{array}$ & $2.293(0.810-6.495)$ & 0.118 \\
\hline $\begin{array}{l}\text { Degree of differentiation } \\
\text { Poor } \\
\text { Well to moderate }\end{array}$ & $0.609(0.276-1.341)$ & 0.218 \\
\hline $\begin{array}{l}\text { Vascular invasion } \\
\text { Absent } \\
\text { Present }\end{array}$ & $1.808(0.752-4.344)$ & 0.186 \\
\hline
\end{tabular}

${ }^{a}$ All statistical tests were two-tailed and the significance level was set as $\mathrm{P}<0.05$.

GC progression. However, the mechanism by which EPAC1 is overexpressed in $\mathrm{GC}$ remain to be investigated.

Cancer cell invasion is mandatory for cancer metastasis, and therefore, it is vital to understand the underlying molecular mechanisms of interest to develop possible treatment options (28). In this study, we found that the overexpression of EPAC1 in GC tissues was closely correlated with depth of invasion and vascular invasion. An in vitro cell invasion assay also demonstrated that the silencing of EAPC1 repressed GC cell invasion. Studies that have explored the role of EPAC1 in cancer invasion are scarce. The expression, distribution, trafficking, and function of integrins are frequently altered in cancer cells in a manner that promotes cancer cell migration (29). Almahariq et al reported that when the expression of EPAC1 in pancreatic cancer cells was knocked down, the ability of the cells to migrate and invade was impaired through the inhibition of the Itg $\beta 1$-related cell adhesion pathway $(30,31)$. Baljinnyam et al conducted a study on melanoma cells and found that EPAC1 could increase $\mathrm{Ca}^{2+}$ release from the endoplasmic reticulum via the activation of inositol triphosphate receptors. The increased $\mathrm{Ca}^{2+}$ then activated
G protein $\beta \gamma$ subunits and promoted cell migration and invasion (32). Whether the mechanism by which EPAC1 promotes GC cell invasion is the same as that in pancreatic cancer and melanoma requires further exploration.

The precise prediction of the risk of recurrence would assist in the minimization of the adverse effects of GC and the maximization of the therapeutic effects of treatment. Of the available prognostic markers for GC, the AJCC stage is the most important. However, the prognosis varies even among patients with the same disease stage; hence, alternative prognostic markers for GC are sought. The role of EPAC1 in tumor prognosis is still unknown. Our results demonstrated that EPAC1 overexpression was associated with poor diseasefree and overall survival and that EPAC1 overexpression was a prognostic marker for GC. Our study was the first to report that the overexpression of EPAC1 can predict poorer outcomes of patients with GC. The overexpression of EPAC1 appears to be a useful marker to predict outcomes of patients with GC who have undergone surgical resection of their tumors. Thus, patients with GC who display overexpression of EPAC1 should be followed up carefully.

A better understanding of the etiology of GC can facilitate the development of new drugs that may be used to treat GC. According to our functional study, the knockdown of EPAC1 inhibited cell invasion. Previous studies have indicated that 3-(5-tert-butylisoxazol-3-yl)-2-[(3-chloro-phenyl)-hydrazono]3-oxo-propionitrile, which is an EPAC-specific antagonist, decreased pancreatic cancer cell migration and invasion $(30,31)$. In the near future, we intend to explore whether this compound has the ability to inhibit GC cell invasion. One limitation of this study was the small sample size of the GC cohort. Accordingly, additional cohort studies would be helpful to confirm our findings.

In summary, this study provides evidence for the clinical significance of EPAC1 overexpression in patients with GC. Our findings indicate that the targeting of EPAC1 might provide a new therapeutic modality for the treatment of GC.

\section{Acknowledgements}

This study was support by the research grant CMFHR 10320 from Chi Mei Medical Center, Tainan, Taiwan (K.-Y.L.). The sponsor had no role in the design of the study and collection, analysis, and interpretation of data or in writing the manuscript.

\section{References}

1. Torre LA, Bray F, Siegel RL, Ferlay J, Lortet-Tieulent J and Jemal A: Global cancer statistics, 2012. CA Cancer J Clin 65: 87-108, 2015

2. Fuchs CS and Mayer RJ: Gastric carcinoma. N Engl J Med 333: 32-41, 1995.

3. Hartgrink HH, Jansen EPM, van Grieken NCT and van de Velde CJ: Gastric cancer. Lancet 374: 477-490, 2009.

4. Vogiatzi P, Vindigni C, Roviello F, Renieri A and Giordano A: Deciphering the underlying genetic and epigenetic events leading to gastric carcinogenesis. J Cell Physiol 211: 287-295, 2007.

5. Lin KY, Fang CL, Chen Y, Li CF, Chen SH, Kuo CY, Tai C and Uen YH: Overexpression of nuclear protein kinase CK2 $\beta$ subunit and prognosis in human gastric carcinoma. Ann Surg Oncol 17: 1695-1702, 2010.

6. Lin KY, Wang LH, Hseu YC, Fang CL, Yang HL, Kumar KJS, Tai $\mathrm{C}$ and Uen $\mathrm{YH}$ : Clinical significance of increased guanine nucleotide exchange factor Vav3 expression in human gastric cancer. Mol Cancer Res 10: 750-759, 2012. 
7. Fang CL,Hseu YC,Lin YF, Hung ST, Tai C, Uen YH and Lin KY: Clinical and prognostic association of transcription factor SOX4 in gastric cancer. PLoS One 7: e52804, 2012.

8. Wang XT, Kong FB, Mai W, Li L and Pang LM: MUC1 immunohistochemical expression as a prognostic factor in gastric cancer: Meta-analysis. Dis Markers 2016: 9421571, 2016.

9. Ren C, Chen H, Han C, Fu D, Wang F, Wang D, Ma L, Zhou L and Han D: The anti-apoptotic and prognostic value of fibroblast growth factor 9 in gastric cancer. Oncotarget 7: 36655-36665, 2016.

10. Burdyga A, Conant A, Haynes L, Zhang J, Jalink K, Sutton R, Neoptolemos J, Costello E and Tepikin A: cAMP inhibits migration, ruffling and paxillin accumulation in focal adhesions of pancreatic ductal adenocarcinoma cells: Effects of PKA and EPAC. Biochim Biophys Acta 1833: 2664-2672, 2013.

11. Cheng X, Ji Z, Tsalkova T and Mei F: Epac and PKA: A tale of two intracellular cAMP receptors. Acta Biochim Biophys Sin (Shanghai) 40: 651-662, 2008.

12. Bos JL: Epac proteins: Multi-purpose cAMP targets. Trends Biochem Sci 31: 680-686, 2006.

13. Grandoch M, Rose A, ter Braak M, Jendrossek V, Rübben H, Fischer JW, Schmidt M and Weber AA: Epac inhibits migration and proliferation of human prostate carcinoma cells. $\mathrm{Br} \mathrm{J}$ Cancer 101: 2038-2042, 2009.

14. Lorenz R, Aleksic T, Wagner M, Adler G and Weber CK: The cAMP/Epac1/Rap1 pathway in pancreatic carcinoma. Pancreas 37: 102-103, 2008.

15. Baljinnyam E, De Lorenzo MS, Xie LH, Iwatsubo M, Chen S, Goydos JS, Nowycky MC and Iwatsubo K: Exchange protein directly activated by cyclic AMP increases melanoma cell migration by a $\mathrm{Ca}^{2+}$-dependent mechanism. Cancer Res 70: $5607-5617,2010$

16. Baljinnyam E, Umemura M, De Lorenzo MS, Iwatsubo M, Chen S, Goydos JS and Iwatsubo K: Epac1 promotes melanoma metastasis via modification of heparan sulfate. Pigment Cell Melanoma Res 24: 680-687, 2011.

17. Baljinnyam E, Umemura M, Chuang C, De Lorenzo MS Iwatsubo M, Chen S, Goydos JS, Ishikawa Y, Whitelock JM and Iwatsubo K: Epac1 increases migration of endothelial cells and melanoma cells via FGF2-mediated paracrine signaling. Pigment Cell Melanoma Res 27: 611-620, 2014.

18. Misra UK and Pizzo SV: Epac1-induced cellular proliferation in prostate cancer cells is mediated by B-Raf/ERK and mTOR signaling cascades. J Cell Biochem 108: 998-1011, 2009.

19. Misra UK and Pizzo SV: Upregulation of mTORC2 activation by the selective agonist of EPAC, 8-CPT-2Me-cAMP, in prostate cancer cells: Assembly of a multiprotein signaling complex. J Cell Biochem 113: 1488-1500, 2012.

20. Menon J, Doebele RC, Gomes S, Bevilacqua E, Reindl KM and Rosner MR: A novel interplay between Rapl and PKA regulates induction of angiogenesis in prostate cancer. PLoS One 7: e49893, 2012.
21. Rangarajan S, Enserink JM, Kuiperij HB, de Rooij J, Price LS, Schwede F and Bos JL: Cyclic AMP induces integrin-mediated cell adhesion through Epac and Rapl upon stimulation of the beta 2-adrenergic receptor. J Cell Biol 160: 487-493, 2003.

22. Bastian P, Balcarek A, Altanis C, Strell C, Niggemann B, Zaenker KS and Entschladen F: The inhibitory effect of norepinephrine on the migration of ES-2 ovarian carcinoma cells involves a Rap1-dependent pathway. Cancer Lett 274: 218-224, 2009.

23. Uen YH, Fang CL, Hseu YC, Shen PC, Yang HL, Wen KS Hung ST, Wang LH and Lin KY: VAV3 oncogene expression in colorectal cancer: Clinical aspects and functional characterization. Sci Rep 5: 9360, 2015.

24. Oliveira FJ, Ferrão H, Furtado E, Batista H and Conceição L: Early gastric cancer: Report of 58 cases. Gastric Cancer 1: 51-56, 1998.

25. de Rooij J, Zwartkruis FJ, Verheijen MH, Cool RH, Nijman SM, Wittinghofer A and Bos JL: Epac is a Rapl guanine-nucleotideexchange factor directly activated by cyclic AMP. Nature 396: 474-477, 1998

26. Kawasaki H, Springett GM, Mochizuki N, Toki S, Nakaya M, Matsuda M, Housman DE and Graybiel AM: A family of cAMP-bindinG proteins that directly activate Rap1. Science 282: 2275-2279, 1998

27. Abate-Shen C and Shen MM: Molecular genetics of prostate cancer. Genes Dev 14: 2410-2434, 2000.

28. Hao F, Tan M, Xu X, Han J, Miller DD, Tigyi G and Cui MZ: Lysophosphatidic acid induces prostate cancer PC3 cell migration via activation of LPA(1), p42 and p38alpha. Biochim Biophys Acta 1771: 883-892, 2007.

29. Caswell PT and Norman JC: Integrin trafficking and the control of cell migration. Traffic 7: 14-21, 2006.

30. Almahariq M, Chao C, Mei FC, Hellmich MR, Patrikeev I, Motamedi $M$ and Cheng X: Pharmacological inhibition and genetic knockdown of exchange protein directly activated by cAMP 1 reduce pancreatic cancer metastasis in vivo. Mol Pharmacol 87: 142-149, 2015.

31. Almahariq M, Tsalkova T, Mei FC, Chen H, Zhou J, Sastry SK, Schwede F and Cheng X: A novel EPAC-specific inhibitor suppresses pancreatic cancer cell migration and invasion. Mol Pharmacol 83: 122-128, 2013.

32. Baljinnyam E, Umemura M, De Lorenzo MS, Xie LH, Nowycky M, Iwatsubo M, Chen S, Goydos JS and Iwatsubo K: G $\beta \gamma$ subunits inhibit Epac-induced melanoma cell migration. BMC Cancer 11: 256, 2011 